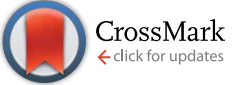

Cite this: RSC Adv., 2017, 7, 9534
Received 18th December 2016 Accepted 27th January 2017

DOI: $10.1039 / c 6 r a 28365 a$

rsc.li/rsc-advances

\section{Formation of Pt-Ag alloy on different silicas - surface properties and catalytic activity in oxidation of methanol $\uparrow$}

\begin{abstract}
Joanna Wisniewska and Maria Ziolek*
The idea of this work was to specify the conditions of alloying silver and platinum loaded on different silicas, i.e. commercial amorphous silica, MCF and NbMCF mesoporous cellular foams and to estimate the influence of the metal species on the activity and selectivity of the catalysts in the oxidation of methanol. For this purpose different amounts of both metals were used for achieving Ag/Pt molar ratios between 1.6 and 5.1. The obtained materials were characterized by nitrogen adsorption isotherms, XRD, TEM, XPS and UV-Vis. The measurements were performed after drying the materials at $333 \mathrm{~K}$, followed by their calcination in air at $773 \mathrm{~K}$ and activation in argon or hydrogen flow at $673 \mathrm{~K}$. Pt-Ag alloy was formed after calcination independently of the structure and composition of the support, if the Ag/Pt molar ratio achieved at least 2.5. On the majority of samples the alloy disappeared after activation in argon or hydrogen flow, with the exception of $0.5 \mathrm{Pt} 2 \mathrm{Ag} / \mathrm{MCF}$ material activated in argon. Structural properties of the support influenced the particle size of the alloy and in this way determined the stability of Pt-Ag alloy in this material. The role of the bimetallic alloy on the activity and selectivity of the catalysts in methanol oxidation is discussed in this paper. The metal species on the supports, sensitive to thermal activation in argon or hydrogen media, did not change during the catalytic oxidation of methanol.
\end{abstract}

\section{Introduction}

Bimetallic nanocrystals, supported on inorganic oxides, appear to be promising in enhancement of activity in many reactions through forming new active sites and inducing synergistic effects. $^{\mathbf{1 , 2}}$ Such materials can exhibit different nanostructures (heterostructure, core-shell, ensemble type, alloy) according to the metal nature and content, metal-support interaction, atmosphere and temperature of activation. ${ }^{1}$ Besides all bimetallic structures, alloy nanoparticles have attracted increasing attention. Alloying causes multiple changes in the physicochemical properties of the metallic components. As far as the catalytic properties are concerned, two effects are important: the ensemble (geometric) and ligand (electronic) effects. The first one defines the number of atoms in a specific geometric orientation required for enhancement of a particular catalytic reaction and the second one concerns modification of the electron density distribution as a consequence of formation of missed bonds. These two effects are usually simultaneously present and lead to improvement of catalytic activity of bimetallic catalysts.,

Adam Mickiewicz University in Poznan, Faculty of Chemistry, ul. Umultowska 89b, 61-614 Poznan, Poland. E-mail: ziolek@amu.edu.pl

$\dagger$ Electronic supplementary information (ESI) available. See DOI: 10.1039/c6ra28365a
It is well known that platinum is one of the best catalysts in oxidation reactions. ${ }^{5}$ However, its high cost and easy poisoning by carbon monoxide are the reasons prompting the search for improvement of Pt-based catalysts properties. The attempts involving alloying of $\mathrm{Pt}$ with other transition metals have been particularly successful and led to the discovery of several promising Pt-based bimetallic catalysts showing improved catalytic activity ${ }^{6-8}$ Silver is another one of the most popular transition metals used for catalytic oxidation..$^{9-12}$ Silver containing alloy nanoparticles also display desired synergistic effect, improving catalytic properties, e.g. $\mathrm{Au}-\mathrm{Ag}$ alloy nanocrystals deposited on different supports display enhanced activity and/or selectivity in oxidation of $\mathrm{CO},{ }^{13,14}$ glucose ${ }^{15}$ and methanol. ${ }^{16}$

The most challenging in preparation of $\mathrm{Pt}-\mathrm{Ag}$ nanocrystals is to make Pt and Ag miscible. ${ }^{17,18}$ According to the phase diagram, it is possible to get an alloy only with a very high atomic content of either $\mathrm{Ag}$ or Pt. However, theoretical and experimental studies show that miscibility between different metals can be greatly increased with decreasing in their particle sizes. ${ }^{18}$ According to literature, $\mathrm{Pt}-\mathrm{Ag}$ alloy nanoparticles can be synthesized by: simultaneous reduction of these metals, ${ }^{17,19-22}$ wet impregnation and further reduction in $\mathrm{H}_{2}$ flow, ${ }^{23}$ radiolytic method, ${ }^{24}$ ion implantation and electrodeposition method. ${ }^{25}$ Because of different reduction kinetics and the thermodynamics the immiscible phase, segregations of Ag atoms on the PtAg alloy surface can be also observed. ${ }^{26,27}$ 
So far the catalyst containing PtAg alloy nanoparticles have been applied mainly in the field of electrocatalysis, especially for electrooxidation of methanol..$^{17,18,20,28-30}$ Besides electrocatalytic application, Hwang et $a l^{23}$ are the only authors who have tested alumina-supported platinum-silver alloy nanoparticle in lowtemperature $\mathrm{CO}$ oxidation. $\mathrm{Pt}-\mathrm{Ag} / \mathrm{Al}_{2} \mathrm{O}_{3}$ catalyst, prepared by wet impregnation, displayed significantly improved activity and largely lowered activation energy barrier when compared to those of both pure Pt and pure Ag catalysts at room temperature. The LangmuirHinshelwood mechanism, in which CO adsorbs to Pt active sites and $\mathrm{O}_{2}$ gets activated on adjacent $\mathrm{Ag}$ sites, has been proposed for the $\mathrm{Pt}-\mathrm{Ag}$ catalyst to explain the promoted $\mathrm{CO}$ oxidation kinetics. The little knowledge about Pt-Ag alloy nanoparticles and their catalytic properties in heterogeneous catalysis has inspired us to focus our studies on this topic.

In our previous work ${ }^{31}$ we have prepared bimetallic (Pt-Ag) catalysts based on MCF mesoporous cellular foams, also modified with $\mathrm{Nb}$ and Ta and applied the so obtained catalysts in methanol oxidation. The intended Ag/Pt atomic ratio was 1.8 (wt $\mathrm{Ag}: \mathrm{Pt}=$ $1: 1)$. In such composition of both metals, the metallic platinum and silver as well as cationic metal species were observed on the support surface depending on the pre-treatment. Moreover, $\mathrm{Pt}-\mathrm{Ag}$ ensembles were recognized. However, Pt-Ag alloy was not formed.

In this work we have changed the bimetallic composition and applied different Ag/Pt ratios with silver used in excess. On the basis of literature, we expected that the formation of platinumsilver alloy would be possible if silver was used in high excess.

Taking into account the results from ref. 31 in this work we applied MPTMS (3-mercaptopropyltrimethoxysilane) as a functionalizing agent used before metals loading and niobium for the modification of MCF support. In the previous work it was shown that the synergistic effects between niobium and silver enhanced the catalyst activity in methanol oxidation and that the catalysts prepared after functionalization with MPTMS were more effective in methanol oxidation than those prepared by functionalization with APTMS (3aminopropyltrimethoxysilane).

The idea of this work was to find the composition of platinum and silver most suitable for the formation of metals alloy, estimate the interaction of metals in alloy with niobium in the support, determine the stability of the alloy and its activity in methanol oxidation. Moreover, the effect of silica structure, amorphous commercial silica vs. mesoporous MCF silica, on the surface and catalytic properties was also analyzed in this work.

\section{Experimental}

\subsection{Synthesis and functionalization of MCF and NbMCF supports}

MCF and NbMCF supports were prepared according to the procedure described in ref. 32 and our previous paper. ${ }^{31}$ Then, the supports were grafted with 3-mercaptopropyltrimethoxysilane (MPTMS) (95\%, Sigma-Aldrich) to functionalize their surface before modification with metals. As a reference support, commercial, amorphous silica (Ultrasil) was used. The details of the preparation protocols are shown in the ESI data. $\uparrow$
Table 1 The examples of notation in catalyst symbols

\begin{tabular}{ll}
\hline Catalyst symbol $^{a}$ & The sequence of treatment conditions $^{\circ}$ \\
\hline $0.5 \mathrm{Pt} 2 \mathrm{Ag} / \mathrm{M}-\mathrm{D}$ & As prepared sample, drying: $333 \mathrm{~K}, 12 \mathrm{~h}$ \\
$0.5 \mathrm{Pt} 2 \mathrm{Ag} / \mathrm{M}$ & Drying: $333 \mathrm{~K}, 12 \mathrm{~h}$ \\
& Calcination in air: $773 \mathrm{~K}, 4 \mathrm{~h}$ \\
$0.5 \mathrm{Pt} 2 \mathrm{Ag} / \mathrm{M}-\mathrm{Ar}$ & Drying: $333 \mathrm{~K}, 12 \mathrm{~h}$ \\
& Calcination in air: $773 \mathrm{~K}, 4 \mathrm{~h}$ \\
& Activation in Ar flow $\left(40 \mathrm{~cm}^{3} \mathrm{~min}^{-1}\right): 673 \mathrm{~K}, 2 \mathrm{~h}$ \\
$0.5 \mathrm{Pt} 2 \mathrm{Ag} / \mathrm{M}-\mathrm{H}_{2}$ & Drying: $333 \mathrm{~K}, 12 \mathrm{~h}$ \\
& Calcination in air: $773 \mathrm{~K}, 4 \mathrm{~h}$ \\
& Activation in $\mathrm{H}_{2}+\mathrm{Ar} \mathrm{flow}^{3}$ \\
& $\left(10 \mathrm{~cm}^{3} \mathrm{~min}^{-1}+30 \mathrm{~cm}^{3} \mathrm{~min}^{-1}\right): 673 \mathrm{~K}, 2 \mathrm{~h}$
\end{tabular}

${ }^{a} \mathrm{D}$ - drying at $333 \mathrm{~K}$, for $12 \mathrm{~h}$. Ar - activation in Ar flow at $673 \mathrm{~K}$, for $2 \mathrm{~h}$, $\mathrm{H}_{2}$ - activation in $\mathrm{H}_{2}$ flow at $673 \mathrm{~K}$, for $2 \mathrm{~h}$.

\subsection{Modification of functionalized supports with platinum and/or silver}

To obtain monometallic and bimetallic catalysts the same procedure as in our previous work ${ }^{31}$ was used, see the ESI data. $\dagger$ In this paper, we used different bimetallic compositions and applied the following $\mathrm{Ag}$ : Pt wt ratios: $1.0: 0.5$, or $2.0: 0.5$, or $2.0: 1.0$ that correspond to the following atomic ratios: $3.6,7.2$, and 3.7, respectively. In the catalysts symbols, the numbers indicate the intended metals weight loading, e.g. 1Pt2Ag/M means the intended $1 \mathrm{wt} \%$ of Pt and $2 \mathrm{wt} \%$ of Ag. In this work, we focused on treatment conditions of modified materials during activation. To clarify the catalysts symbols reference to different treatment conditions, Table 1 gives the activation conditions for each material used in this work.

\subsection{Activation of catalysts}

Before methanol oxidation, the samples were activated in the flow of argon $\left(40 \mathrm{~cm}^{3} \mathrm{~min}^{-1}\right)$ or mixture of hydrogen and argon $\left(10+30 \mathrm{~cm}^{3} \mathrm{~min}^{-1}\right)$. For this purpose, the samples in the form of powder were pressed $(<2 \mathrm{MPa})$, crushed and the fraction of particles from 0.5 to $1.0 \mathrm{~mm}$ was collected to be used in the reaction. The $0.04 \mathrm{~g}$ of the sample was put into the flow-bed reactor (length $l=70 \mathrm{~mm}$ and $\varnothing=5 \mathrm{~mm}$ ) and the catalyst was heated from room temperature to $673 \mathrm{~K}$ at a rate $10 \mathrm{~K}$ $\min ^{-1}$. Then the sample was activated for $2 \mathrm{~h}$ at $673 \mathrm{~K}$.

\subsection{Characterization}

The materials prepared were characterized by using ICP-OES, $\mathrm{N}_{2}$ adsorption/desorption, Transmission Electron Microscopy (TEM), $\mathrm{X}$-ray diffraction (XRD), X-ray fluorescence (XRF), ultravioletvisible (UV-Vis) spectroscopy, and X-ray photoelectron spectroscopy (XPS). All these techniques are described in details in the ESI data (S3-SD $\dagger$ ), according to our previous papers. ${ }^{31,33}$ Catalysts after activation and methanol oxidation were characterized by X-ray diffraction, ultraviolet-visible (UV-Vis) spectroscopy and Scanning Transmission Electron Microscopy (STEM).

\subsection{Methanol oxidation}

Catalytic reaction was performed in fixed-bed flow reactor, as described in our previous works ${ }^{31,33}$ and ESI data (S4-SD †). This 
time, we focused on the effect of pretreatment conditions on catalytic activity of prepared bimetallic systems. Thus, before catalytic reaction, samples were activated in $\mathrm{Ar}$ or $\mathrm{H}_{2}+\mathrm{Ar}$ mixture at $673 \mathrm{~K}$ for $2 \mathrm{~h}$.

The following products detected by FID and TCD detectors were taken into account: methanol, formaldehyde, methyl formate, dimethoxymethane, dimethyl ether, and carbon dioxide. The carbon balance was $c a$. 95\%. The product distribution was illustrated by selectivities.

\section{Results and discussion}

\subsection{Composition and structure of catalysts}

It is known that the isomorphous substitution of niobium into MCF mesoporous cellular foams is not an effective process and usually ca. 2.5 times less niobium is incorporated to MCF silica than the amount used in the preparation procedure. ${ }^{31,34}$ In this work the $\mathrm{Si} / \mathrm{Nb}$ atomic ratio achieved in NbMCF support was 159 (the intended value was 64). The amounts of platinum and silver loaded on three supports: MCF (denoted as M), NbMCF (indicated as $\mathrm{NbM}$ ) and commercial silica (denoted as $\mathrm{Si}$ ) are shown in Table 2.

The use of MPTMS as a functionalizing agent anchored to the supports before metals loading allowed the incorporation of platinum with $100 \%$ efficiency. In contrast, the efficiency of silver loading was mostly lower and depended on the amount of platinum in the mixture of modifiers and the composition of the support. The presence of niobium in NbMCF support enhanced the incorporation of silver because of strong silver-niobium interaction described in ref. 31 and observed also in this work. The higher amount of platinum ( $1 \mathrm{wt} \%$ instead of $0.5 \mathrm{wt} \%$ ) lowered the efficiency of silver loading because of the higher chemical affinity of thiol groups to platinum than to silver species resulted in a stronger interaction between SH end-group in MPTMS and the platinum source (chloroplatinic ion). However, even without platinum, silver loading did not reach $100 \%$.

For the same intended composition of metals content, $0.5 \mathrm{Pt} 1 \mathrm{Ag} / \mathrm{support}$, or $0.5 \mathrm{Pt} 2 \mathrm{Ag} / \mathrm{support}$, or $1 \mathrm{Pt} 2 \mathrm{Ag} / \mathrm{support}$, the real $\mathrm{Ag} / \mathrm{Pt}$ atomic ratio was much higher on NbMCF than on MCF support. Moreover, for the same intended $\mathrm{Ag} / \mathrm{Pt}$ wt ratio equal to 2.0, the real Ag/Pt ratio was much higher if lower amounts of both modifiers were used (0.5Pt1Ag/support instead of $1 \mathrm{Pt} 2 \mathrm{Ag} /$ support) irrespective of the nature of the support. In each series of the catalysts based on different supports, the highest real $\mathrm{Ag} / \mathrm{Pt}$ molar ratio was on $0.5 \mathrm{Pt} 2 \mathrm{Ag} / \mathrm{support}$ (4.2 for $\mathrm{MCF}$ support and 5.1 for two other supports). Thus, not only the ratio of metals in the modifiers mixture but also the amount of each metal source determined the final ratio between silver and platinum. Both parameters influenced the stability of metal species.

The calculation of metal contents from XPS spectra gives information about the metal concentrations on the surface of the materials. A comparison between the content of platinum and silver species in the bulk (calculated from ICP OES) and on the surface (estimated from XPS spectra) is shown in Table S1$\mathrm{SD} . \dagger$ It is clear that the concentration of platinum and silver on the surface is much lower than in the bulk which indicates that the preferential location of metals is in pores.

Table 2 The composition of calcined catalysts (measured by ICP OES) and efficiency of silver loading

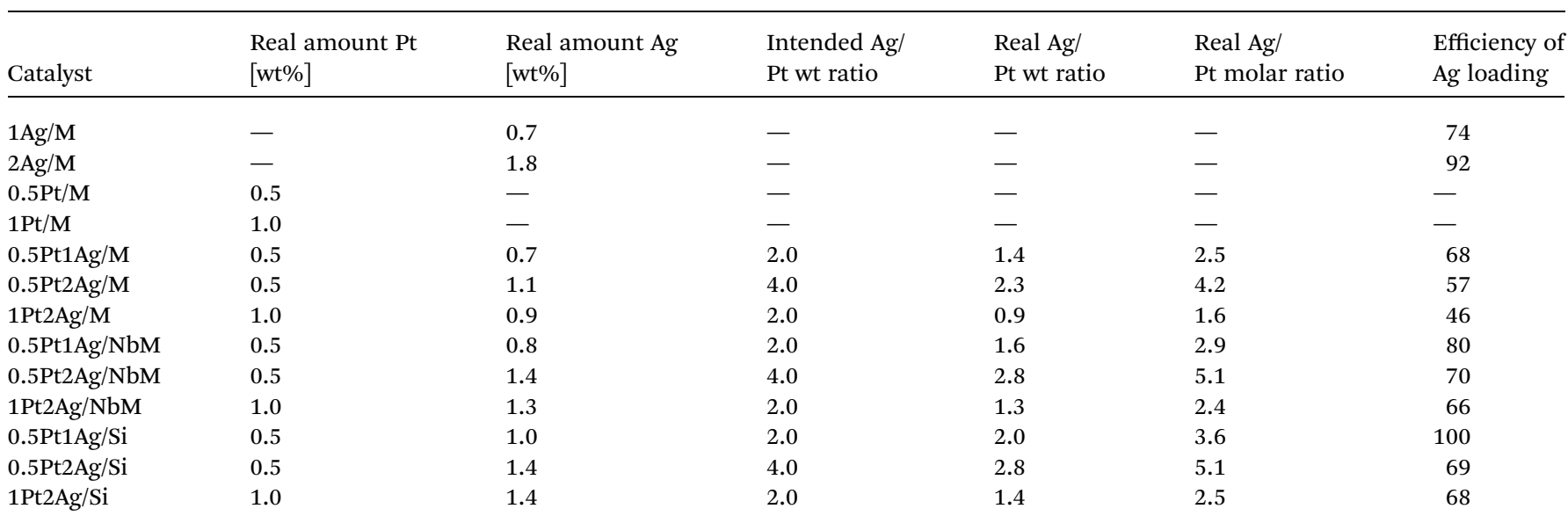

Table 3 Texture of the selected materials estimated from nitrogen adsorption/desorption isotherms

\begin{tabular}{lllll}
\hline Catalyst & BET surface area $\left[\mathrm{m}^{2} \mathrm{~g}^{-1}\right]$ & Mean cell diameter ${ }^{a}[\mathrm{~nm}]$ & Mean window diameter $^{b}\left[\mathrm{~nm}^{-}\right.$ & Mean pore volume $\left[\mathrm{cm}^{3} \mathrm{~g}^{-1}\right]$ \\
\hline $\mathrm{MCF}$ & 655 & 39.5 & 19.7 & 2.8 \\
$\mathrm{NbMCF}$ & 796 & 36.6 & 11.2 & 2.7 \\
$1 \mathrm{Pt} 2 \mathrm{Ag} / \mathrm{MCF}$ & 409 & 36.3 & 15.7 & 1.7 \\
$\mathrm{SiO}_{2}$ & 158 & - & - & 1.6
\end{tabular}

${ }^{a}$ Calculated from adsorption branch. ${ }^{b}$ Calculated from desorption branch. 
The structural parameters calculated from nitrogen adsorption/ desorption isotherms are shown in Table 3 for the supports and the MCF mesoporous cellular foam loaded with the highest amounts of platinum and silver. MCF material exhibits high cell and window diameters. Interestingly, the decrease in window diameter was much higher than in the cell one after modification of MCF with niobium species. This proves that niobium present in the synthesis gel modified the structural parameters of mesoporous cellular foam, mainly the window size. It is supported by the shape of the hysteresis loop much wider for NbMCF than for MCF sample (Fig. S1-SD†). The mean pore volume was almost the same for MCF and NbMCF materials, whereas platinum and silver loading on MCF led to a significant decrease in the mean pore volume and surface area but only slightly changed the cell and window sizes. It indicates that both metals were located inside the pores. The surface area and mean pore volume of commercial silica were much lower than those in both MCF and NbMCF samples.

\subsection{Surface properties and stability of Pt-Ag alloy}

The contents of platinum and silver species were estimated on the basis of XRD, UV-Vis DRS, and XPS study. The studies were carried out after different pre-treatments of the samples modified with platinum and/or silver species, namely after (i) drying at $333 \mathrm{~K}$ for $12 \mathrm{~h}$, (ii) drying at $333 \mathrm{~K}$ for $12 \mathrm{~h}$ and calcination at $773 \mathrm{~K}$ for $4 \mathrm{~h}$, (iii) followed by activation at $673 \mathrm{~K}$ for $2 \mathrm{~h}$ in inert gas (Ar), (iv) and activation in reducing mixture $\left(10 \mathrm{~cm}^{3} \mathrm{H}_{2}\right.$ and $30 \mathrm{~cm}^{3} \mathrm{Ar}$ ) i.e. in the conditions applied for activation before oxidation of methanol.

3.2.1. Characterization of surface properties of dried and calcined materials. XRD patterns of dried monometallic materials do not show any reflexes (Fig. 1) suggesting high dispersion of platinum and silver species in freshly synthesized materials (after drying) in amorphous state. After calcination, three peaks at: $c a .32^{\circ}, 33^{\circ}$, and $34^{\circ}$ in the diffractograms indicate the presence of $\mathrm{Ag}_{2} \mathrm{O}$ and/or oxidized platinum species. ${ }^{35,36}$ It is difficult to distinguish the peaks originated from platinum oxides and those from silver oxide in the diffractograms of bimetallic samples because the XRD peaks characteristic of them are located very close to each other as shown in Fig. S2$\mathrm{SD} . \dagger$ In the diffractograms of calcined monometallic platinum containing materials, besides the reflexes from platinum oxides, the peaks at $2 \theta=39.8^{\circ}$ and $46.2^{\circ}$ appeared and they were assigned to metallic platinum particles. They come from (111) and (200) faces, respectively ${ }^{36}$ (JCPDS no. 04-0802).

In the diffractograms of dried bimetallic samples the presence or absence of XRD peaks depends on the nature of the support and the amount of silver species introduced (Fig. 1 and S3-SD †). Three materials, 1Pt2Ag/M-D, 0.5Pt2Ag/Si-D, and $1 \mathrm{Pt} 2 \mathrm{Ag} / \mathrm{Si}-\mathrm{D}$, revealed two reflexes from (111) and (200) faces around $2 \theta=38.1^{\circ}$ and $44.1^{\circ}$ in XRD patterns. These reflexes were assigned to metallic silver particles ${ }^{37}$ (JCPDS no. 04-073). They appeared only on silica supports (MCF and amorphous $\mathrm{SiO}_{2}$ ) and when using the excess of silver. One cannot exclude the presence of metallic silver and platinum in all the samples but they are highly dispersed so they do not give any reflexes in XRD pattern. Interestingly, on NbMCF support loaded by silver and platinum, no dried sample showed XRD peaks suggesting very high dispersion of both metallic species on this support.

Calcination (treatment at $773 \mathrm{~K}$ in air) of the dried materials totally changed the XRD patterns (Fig. 1 and S3-SD†). The diffractograms of dried materials exhibited XRD peaks from metallic silver, while the XRD pattern after calcination showed the disappearance of metallic silver and the appearance of peaks characteristic of $\mathrm{Ag}_{2} \mathrm{O}$ at $2 \theta=32.9^{\circ}$ and $33.9^{\circ}$ (ref. 35) [JCPDS 76-1393]. The third reflex at $c a .31 .8^{\circ}$ can originate from both, platinum and silver oxides. The peaks assigned to metal oxides are present in the XRD patterns of all calcined materials. Moreover, in all XRD patterns of calcined materials two reflexes at $39.8^{\circ}(111)$ and $46.23^{\circ}$ (200) come from metallic platinum
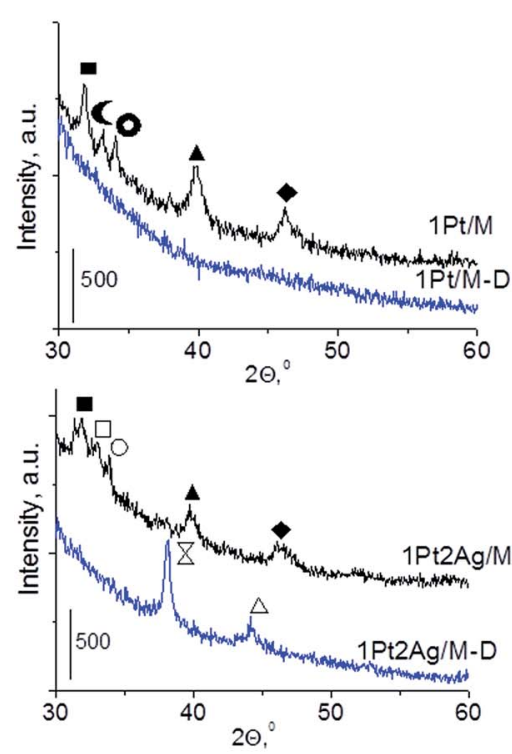
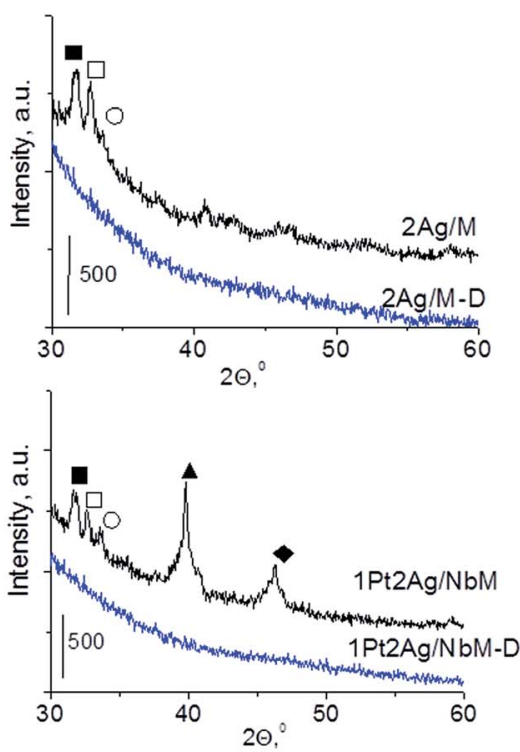
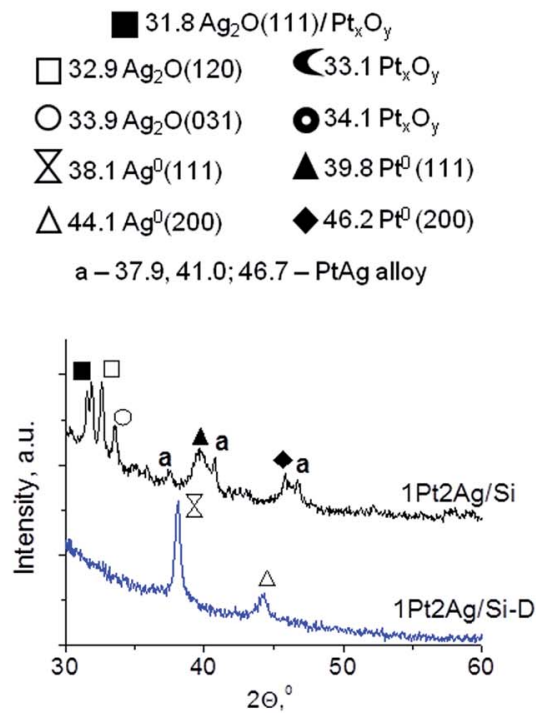

Fig. 1 XRD patterns of mono and bimetallic catalysts after drying at $333 \mathrm{~K}$ (denoted as $\mathrm{D}$ ) and calcination at $773 \mathrm{~K}$. 

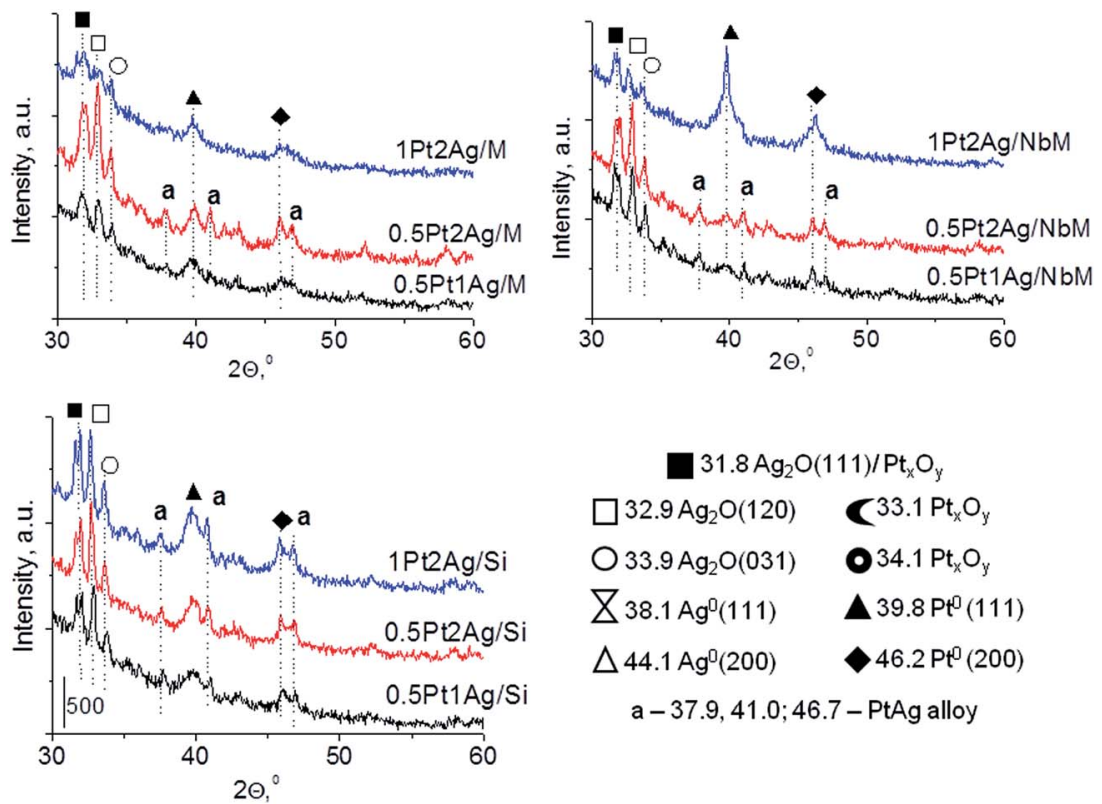

Fig. 2 Comparison of XRD patterns of Pt-Ag bimetallic catalysts (calcined at $773 \mathrm{~K}$ ) based on the same support, but with different metals loading.
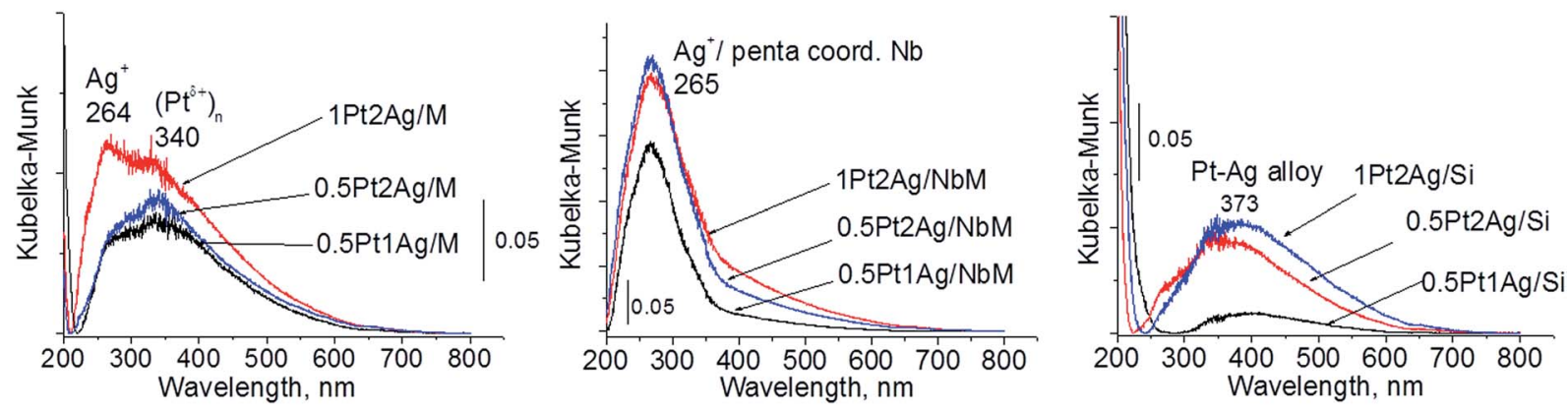

Fig. 3 UV-Vis DR spectra of the catalysts based on three different supports after calcination at $773 \mathrm{~K}$.

species $^{36,38}$ (JCPDS no. 04-0802). It means that calcination caused agglomeration of metallic platinum to the particle size detected in XRD technique. A significant change in XRD patterns after calcination of the materials also involves the appearance of new XRD peaks at $2 \theta=37.7^{\circ}, 40.9^{\circ}$, and $46.8^{\circ}$. According to literature $\mathrm{e}^{23,39}$ the peaks positioned between those assigned to pure Pt and pure Ag indicate $\mathrm{Pt}-\mathrm{Ag}$ alloy formation. Thus the XRD patterns of calcined materials (Fig. 2) indicate the presence of both metallic forms, Pt-Ag alloy and separated metallic platinum besides the platinum and silver oxides. It is clearly seen that only $1 \mathrm{Pt} 2 \mathrm{Ag} / \mathrm{M}$ and $1 \mathrm{Pt} 2 \mathrm{Ag} / \mathrm{NbM}$ samples do not show well separated peaks from Pt-Ag alloy but these peaks can be covered by shoulders in the XRD patterns. These two materials show the lowest $\mathrm{Ag} / \mathrm{Pt}$ molar ratio: 1.6 and 2.4, respectively (Table 2). A comparison of intensity of the reflexes assigned to Pt-Ag alloy and ICP-OES data indicates that the excess of silver in relation to platinum is necessary for the formation of $\mathrm{Pt}-\mathrm{Ag}$ alloy. However, $1 \mathrm{Pt} 2 \mathrm{Ag} / \mathrm{Si}$ calcined material exhibits very well distinguished XRD peaks originated from Pt$\mathrm{Ag}$ alloy despite the relatively low atomic ratio of silver to platinum (2.5). Thus, one can conclude that the structure of the support plays also an important role in the alloy formation. The most intense reflexes were observed for the samples with high $\mathrm{Ag} / \mathrm{Pt}$ molar ratio (e.g. $0.5 \mathrm{Pt} 2 \mathrm{Ag} / \mathrm{M}-\mathrm{Ag} / \mathrm{Pt}=4.6 ; 0.5 \mathrm{Pt} 2 \mathrm{Ag} / \mathrm{NbM}-$ $\mathrm{Ag} / \mathrm{Pt}=5.1$ ). Thus, the excess of silver in relation to platinum is crucial for the alloy formation and the structure of the support is also an important feature. Platinum-silver alloy was not observed in the materials previously studied ${ }^{31}$ in which $\mathrm{Ag} / \mathrm{Pt}$ molar ratio was 1.8. UV-Vis diffuse reflectance spectroscopy (UV-Vis DRS) allowed the observation of bands assigned to charge transfers in metallic species (Fig. 3). As regards the bimetallic materials based on amorphous silica and MCF, the UV-Vis DR spectra of fresh, calcined samples revealed complex broad bands with well distinguished two maxima at $264 \mathrm{~nm}$ and $340 \mathrm{~nm}$. The first band can be due to the charge transfer $\mathrm{n}^{*} \rightarrow$ $\mathrm{d}$ in the unreduced $\mathrm{Pt}^{2+},{ }^{40}$ or to $\mathrm{d}-\mathrm{d}$ electron transfer in platinum nanoparticles, or to $4 \mathrm{~d}^{10} \rightarrow 4 \mathrm{~d}^{9} \mathrm{~s}^{1}$ transition characteristic of well-dispersed $\mathrm{Ag}^{+}$cations and/or small $\mathrm{Ag}_{n}{ }^{\delta+}$ clusters. ${ }^{\mathbf{4 1}}$ Both charge transfers in silver species gave rise to a band at $c a$. $340 \mathrm{~nm}$. The latter band can also originate from transition in 
$\mathrm{Pt}_{n}{ }^{\delta+}$ clusters. The long tails in the region of higher wavelengths can cover the band characteristic of $\mathrm{d}-\mathrm{d}$ electron transfer in Pt$\mathrm{Ag}$ alloy. ${ }^{39,42}$ Such a band is well visible in the UV-Vis DR spectra of the materials based on amorphous silica. The use of NbMCF support did not allow the observation of bands coming from charge and electron transfers in silver and platinum species because the band assigned to the charge transfer in pentacoordinated niobium species dominated (the band at $265 \mathrm{~nm}$ ). ${ }^{43}$

More information about the oxidation state of the catalyst components could be obtained from XPS study. As concerns silver species, XP spectra appeared to be complicated. The investigated region between $366 \mathrm{eV}$ and $378 \mathrm{eV}$ covers binding energies of $\mathrm{Ag} 3 \mathrm{~d}_{5 / 2}$ and $\mathrm{Ag} 3 \mathrm{~d}_{3 / 2}$ reported for $\mathrm{Ag}^{\mathrm{O}}, \mathrm{Ag}_{2} \mathrm{O}$ and $\mathrm{AgO}{ }^{44-47}$ Cationic silver species are identifiable much more easily by their peak shape and width than by their absolute energy. Fig. S4-SD $\dagger$ presents the XP spectra of the samples with the highest metal loadings. They reveal the interaction of silver with niobium species located in the NbMCF support, whose presence is concluded from the shift of binding energies (BE) to higher values. The XP spectra of platinum $\mathrm{Pt}_{4 / 2}$ and $\mathrm{Pt}_{7 / 2} \mathrm{f}_{5 / 2}$ for the selected samples are shown in Fig. 4. The spectrum of the monometallic platinum sample presented the XPS bands characteristic of metallic and cationic $\left(\mathrm{Pt}^{2+}\right)$ platinum species. In bimetallic samples metallic platinum was also detected but its binding energy was higher than that typical of monometallic platinum; the shift for $\mathrm{Pt}_{4 / 2}$ : from $70.3 \mathrm{eV}$ for monometallic $0.5 \mathrm{Pt} / \mathrm{M}$ sample to $71.5 \mathrm{eV}, 71.6 \mathrm{eV}$, and $71.3 \mathrm{eV}$ for $0.5 \mathrm{Pt} 2 \mathrm{Ag} / \mathrm{M}, 0.5 \mathrm{Pt} 2 \mathrm{Ag} / \mathrm{NbM}$, and $0.5 \mathrm{Pt} 2 \mathrm{AgSi}$, respectively. According to literature ${ }^{48-50}$ all these values are in the range typical of metallic platinum. However, the value of $\mathrm{BE}$ is an indicator of the binding strength which depends on the particle size $^{51}$ and the type of surrounding. ${ }^{33,52}$ The higher BE in bimetallic samples indicates the stronger binding of platinum which occurs in Pt-Ag alloy. Interestingly, the bimetallic sample based on silica revealed in its XP spectrum only metallic platinum in the alloy, whereas for two other samples based on MCF and NbMCF additional cationic platinum $(4+)$ was detected.
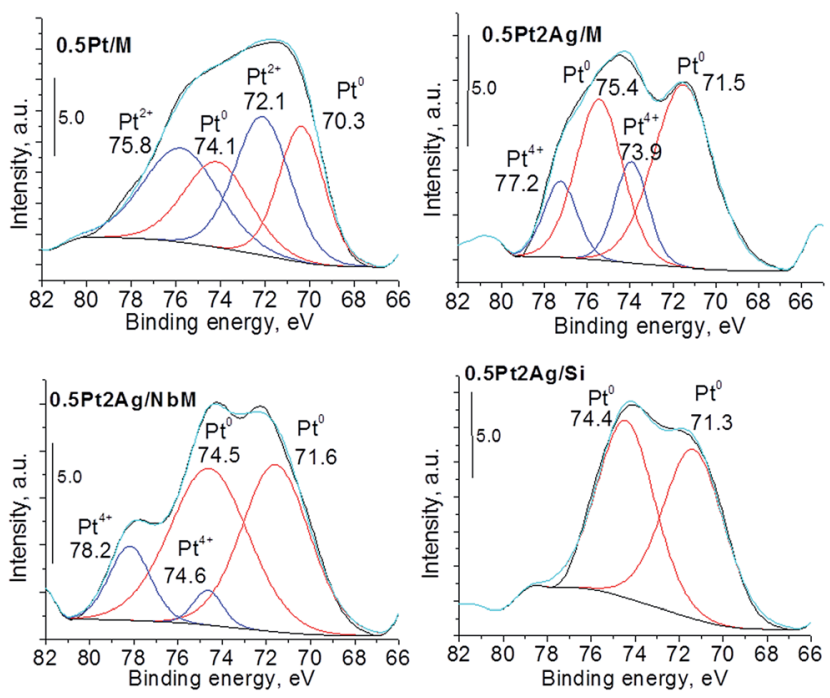

Fig. 4 Pt4f $X P$ spectra of monometallic and bimetallic selected samples (the samples after calcination in air at $773 \mathrm{~K}$ ).
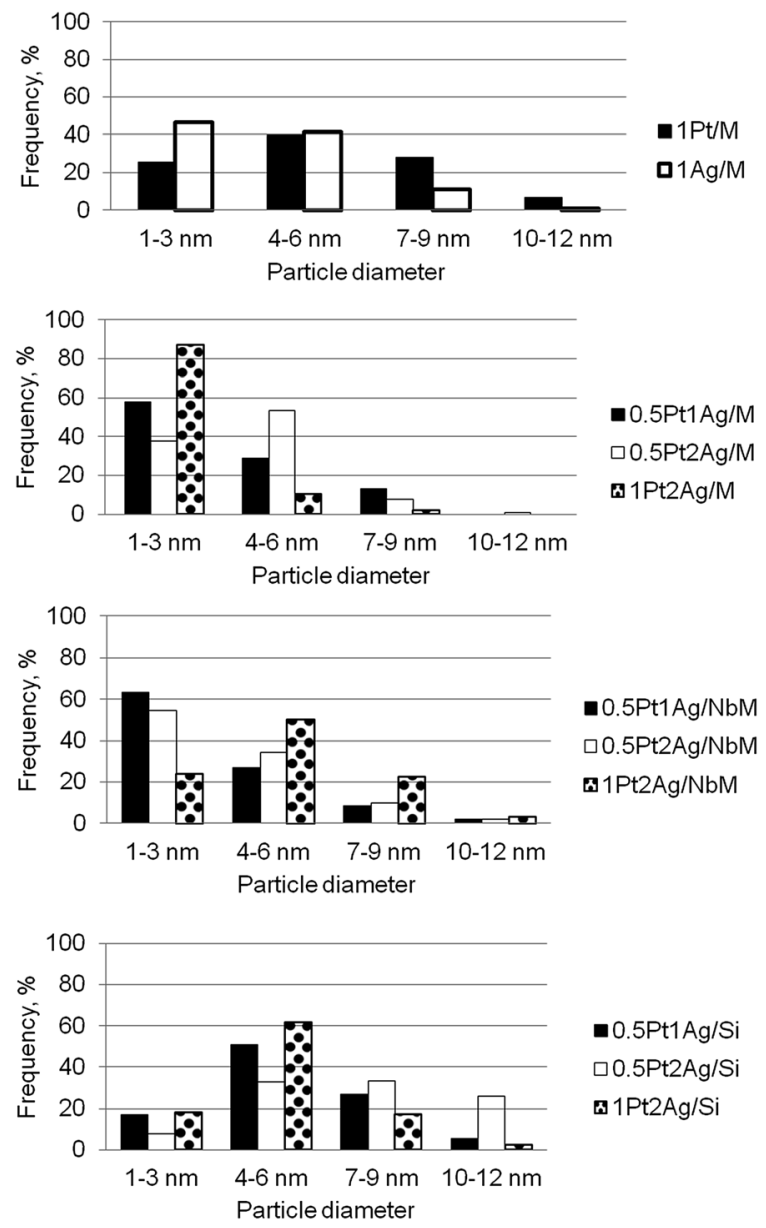

Fig. 5 Metal particle size distribution - calculated from TEM images.

Metal particle sizes were calculated from TEM images (the examples of images are shown in Fig. S5-SD $\dagger$ ). Of course, TEM images did not allow us to distinguish between single metallic and bimetallic particles, but they gave general overview concerning the sizes of metallic and bimetallic clusters. Fig. 5 shows the metal particle size distribution in the calcined monometallic and bimetallic samples. In monometallic materials loaded on MCF, silver dispersion was much better than platinum one for the similar metal loading (in $1 \mathrm{Pt} / \mathrm{M}$ and $1 \mathrm{Ag} / \mathrm{M}$ samples the greatest population of silver cluster sizes was in the range of 1-3 nm). Bimetallic samples reveal better dispersion of metallic clusters than monometallic samples. Particle size distribution depends on both, the nature of the support and the metal loading. On the basis of diagrams in Fig. 5 one can draw the information on the orders of population of the smallest (1-3 $\mathrm{nm}$ ) metallic clusters depending on metal loading. The loading with $0.5 \mathrm{Pt} 1 \mathrm{Ag}$ and $0.5 \mathrm{Pt} 2 \mathrm{Ag}$ led to the following sequence of supports according to the population of the smallest clusters: $\mathrm{NbMCF}>\mathrm{MCF}>\mathrm{SiO}_{2}$; whereas for $1 \mathrm{Pt} 2 \mathrm{Ag}$ samples the best dispersion was achieved on MCF support (MCF > NbMCF > $\mathrm{SiO}_{2}$ ). For all metal loadings the lowest dispersion was obtained on amorphous silica because this support favors agglomeration of metal particles. Thus, the structure of mesoporous cellular foams promoted dispersion of metals. The incorporation of 

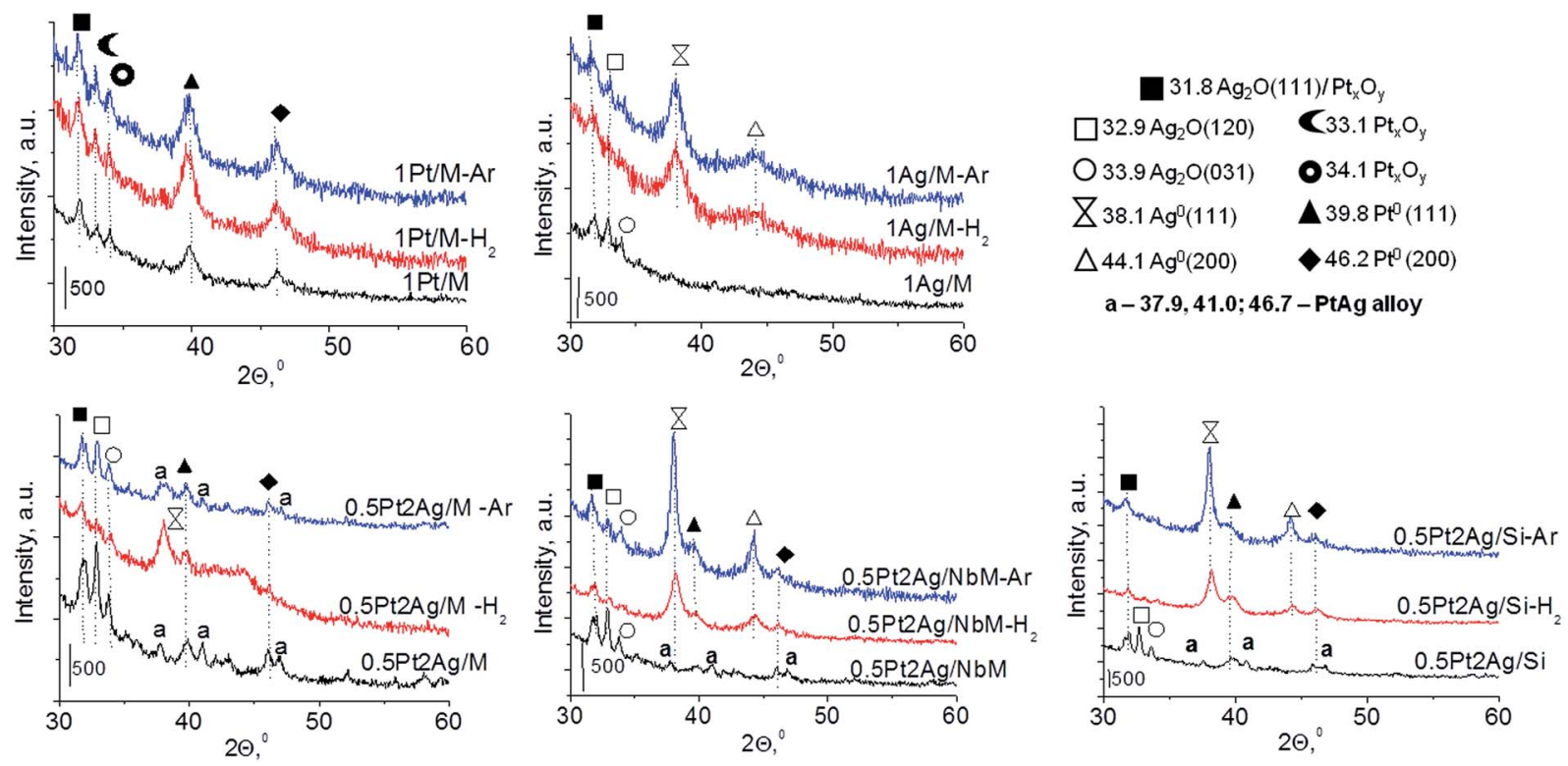

Fig. 6 Comparison of XRD patterns of the selected samples after calcination at $773 \mathrm{~K}$, activation at $673 \mathrm{~K}$ under hydrogen and argon flow.

niobium into MCF material enhanced the dispersion of metals because of the interaction between niobium and metals loaded which was documented by UV-Vis DRS and XPS results. The exception was the sample with the highest metal loading (1Pt2Ag/NbM) in which the dispersion of metals was much lower than that on the material without niobium, $1 \mathrm{Pt} 2 \mathrm{Ag} / \mathrm{M}$. This phenomenon is caused by much lower window diameter $(11.2 \mathrm{~nm})$ in NbMCF support than in MCF $(19.7 \mathrm{~nm})$ as shown in Table 3. The lowering of window diameter caused difficulties in penetration of metals into the cells if the loading by silver and platinum was high. In this way the structure of NbMCF promoted the agglomeration of metals clusters under higher concentration of metals.

3.2.2. Characterization of surface properties of materials activated under argon or hydrogen flow. The stability of $\mathrm{Pt}-\mathrm{Ag}$ alloy and other metal species was estimated by XRD measurements after thermal (673 K) treatment of the samples under argon or hydrogen flow (Fig. 6 and S6-SD $\dagger$ ). Such treatments led to the disappearance of XRD peaks from the alloy in the diffractograms of most samples with the exception of $0.5 \mathrm{Pt} 2 \mathrm{Ag} / \mathrm{M}-\mathrm{Ar}$ which is the material activated in argon flow. The activation of the same sample in hydrogen flow did not allow the preservation of the alloy (visible in XRD pattern) because under stronger reduction conditions (hydrogen flow) silver from both species, $\mathrm{Ag}_{2} \mathrm{O}$ and Pt$\mathrm{Ag}$ alloy, is reduced to metallic one characterized by XRD peaks at $38.1^{\circ}$ and $44.1^{\circ}$. Generally, the appearance of metallic silver (very intense XRD peak at $38.1^{\circ}, \mathrm{Ag}^{0}(111)$ ) after activation was accompanied by a significant decrease in intensity of the peaks characteristic of $\mathrm{Ag}_{2} \mathrm{O}$. The changes in XRD peaks assigned to metallic platinum were not significant. Therefore, one can conclude that the disappearance of peaks coming from $\mathrm{Pt}-\mathrm{Ag}$ alloy was not caused by the total separation of platinum and silver but rather by their segregation and formation of ensembles instead of alloys like it was observed for other bimetallic PtAg

systems. $^{26,27,53}$ STEM measurements and EDX analysis were performed to check if after activation in hydrogen flow small alloy particles, not visible in XRD patterns, were preserved. STEM-EDX images (Fig. S7-SD $\dagger$ ) of $0.5 \mathrm{Pt} 2 \mathrm{Ag} / \mathrm{M}-\mathrm{H}_{2}$ showed the segregated $\mathrm{Ag}$ and Pt particles. The role of niobium in the support is evident in activated samples. Niobium species led to the agglomeration of metallic silver, as deduced from the intensive, sharp peaks characteristic of metallic silver. The question arises why Pt-Ag alloy is preserved on $0.5 \mathrm{Pt} 2 \mathrm{Ag} / \mathrm{M}$-Ar activated in argon flow. MCF support exhibited the highest cell and window diameters which favored the agglomeration of alloy towards larger particles. Both, a significant excess of silver and the structure of the support are important for the stability of alloy particles. The calculation of alloy particle sizes from XRD peaks using the Scherrer formula ${ }^{54}$ supports the above conclusion. Table 4 shows the highest crystal size $(18.8 \mathrm{~nm})$ for $0.5 \mathrm{Ag} 2 \mathrm{Pt} / \mathrm{M}$ which was partially reduced after activation in argon flow. UV-Vis DR study brought additional information about changes in the state of silver and platinum species that resulted from the activation in argon or hydrogen flow. Fig. 7 shows the spectra of monometallic materials based on MCF. The activation conditions did not influence the state of platinum species. The two UV-Vis bands at $256 \mathrm{~nm}$ and $c a .320 \mathrm{~nm}$ are present in the spectra irrespective of the temperature treatment of the samples under different atmospheres. The first band

Table 4 Mean particle size of Pt-Ag alloy in calcined (773 K in air) samples and after activation ( $673 \mathrm{~K}$ in argon flow), calculated from XRD peak at $41.0^{\circ}$, according to Scherrer formula

\section{Catalyst} Alloy particle size $[\mathrm{nm}]$ from XRD

$0.5 \mathrm{Pt} 2 \mathrm{Ag} / \mathrm{M}$

$0.5 \mathrm{Pt} 2 \mathrm{Ag} / \mathrm{M}-\mathrm{Ar}$

$0.5 \mathrm{Pt} 2 \mathrm{Ag} / \mathrm{NbM}$

$0.5 \mathrm{Pt} 2 \mathrm{Ag} / \mathrm{Si}$
18.8

15.7

15.1

17.3 

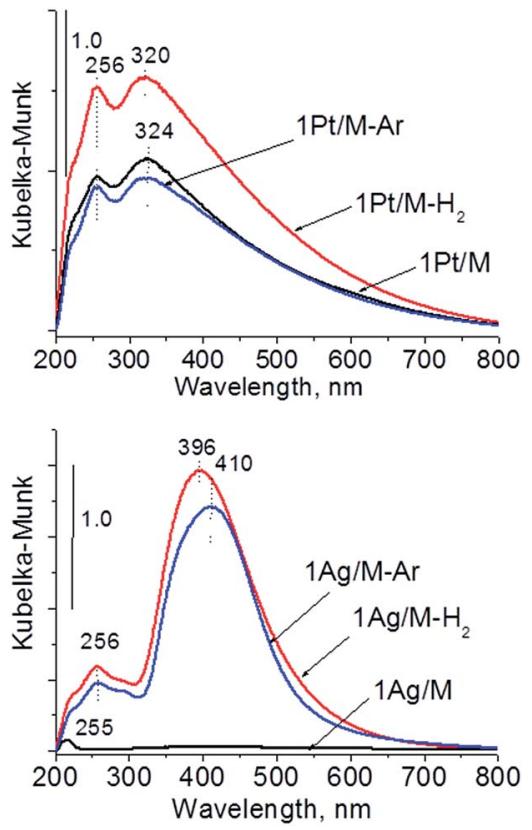

Fig. 7 UV-Vis DR spectra of monometallic samples after calcination and activation under argon or hydrogen flow.

comes from the charge transfer $\mathrm{n}^{*} \rightarrow \mathrm{d}$ in the unreduced $\mathrm{Pt}^{2+}{ }^{20}$ or to $d-d$ electron transfer in platinum nanoparticles, whereas the second is assigned to transition in $\mathrm{Pt}_{n}{ }^{\delta+}$ clusters. This observation is in agreement with the results of XRD study shown in Fig. 6. In contrast, the UV-Vis spectra of silver containing sample significantly changed after activation in argon or hydrogen flow. Both activation conditions led to the appearance of the intense band at ca. $400 \mathrm{~nm}$ and a lower intensity band at $256 \mathrm{~nm}$. The first is typical of surface plasmon resonance (SPR) in metallic silver clusters. The second is due $4 \mathrm{~d}^{10} \rightarrow 4 \mathrm{~d}^{9} \mathrm{~s}^{1}$ transition characteristic of well dispersed $\mathrm{Ag}^{+}$cations. ${ }^{41}$ Such UV-Vis results support the above described results of XRD study shown in Fig. 6. The red shift of the band characteristic of metallic silver, from $396 \mathrm{~nm}$ for $1 \mathrm{Ag} / \mathrm{M}-\mathrm{H}_{2}$ to $410 \mathrm{~nm}$ for $1 \mathrm{Ag} / \mathrm{M}-\mathrm{Ar}$ is caused by the larger metal particles formed on the material activated under argon flow. Most probably the faster reduction which occurs under hydrogen flow favored the formation of smaller metal particles.

The UV-Vis spectra of bimetallic samples based on MCF and NbMCF supports are shown in Fig. 8. In all spectra two parts can be distinguished, one at lower wavelengths (at $c a .260 \mathrm{~nm}$ ) showing the bands from charge transfer in cationic silver, platinum or niobium species and the second region typical of SPR in metallic silver (at $c a .400 \mathrm{~nm}$ ). Typically after activation in hydrogen flow a very intense band characteristic of metallic silver appeared, whereas this band was less pronounced after activation in argon flow. From all the UV-Vis spectra the one for $0.5 \mathrm{Pt} 2 \mathrm{Ag} / \mathrm{M}$-Ar stands out. It does not reveal well-developed band characteristic of metallic silver, which is in agreement with the XRD pattern of this sample (Fig. 6) which showed the presence of peaks from Pt-Ag alloy and the absence of reflexes from metallic silver. The changes in the state of metal modifiers after thermal treatments under hydrogen or argon flow, which were evidenced by XRD and UV-Vis DRS study, should determine the activity and/or selectivity in catalytic processes.

\subsection{Methanol oxidation}

Taking into account the above described surface properties of bimetallic materials we chose the samples with the modifiers composition of $0.5 \mathrm{Pt} 2 \mathrm{Ag}$ loaded on different supports and tested
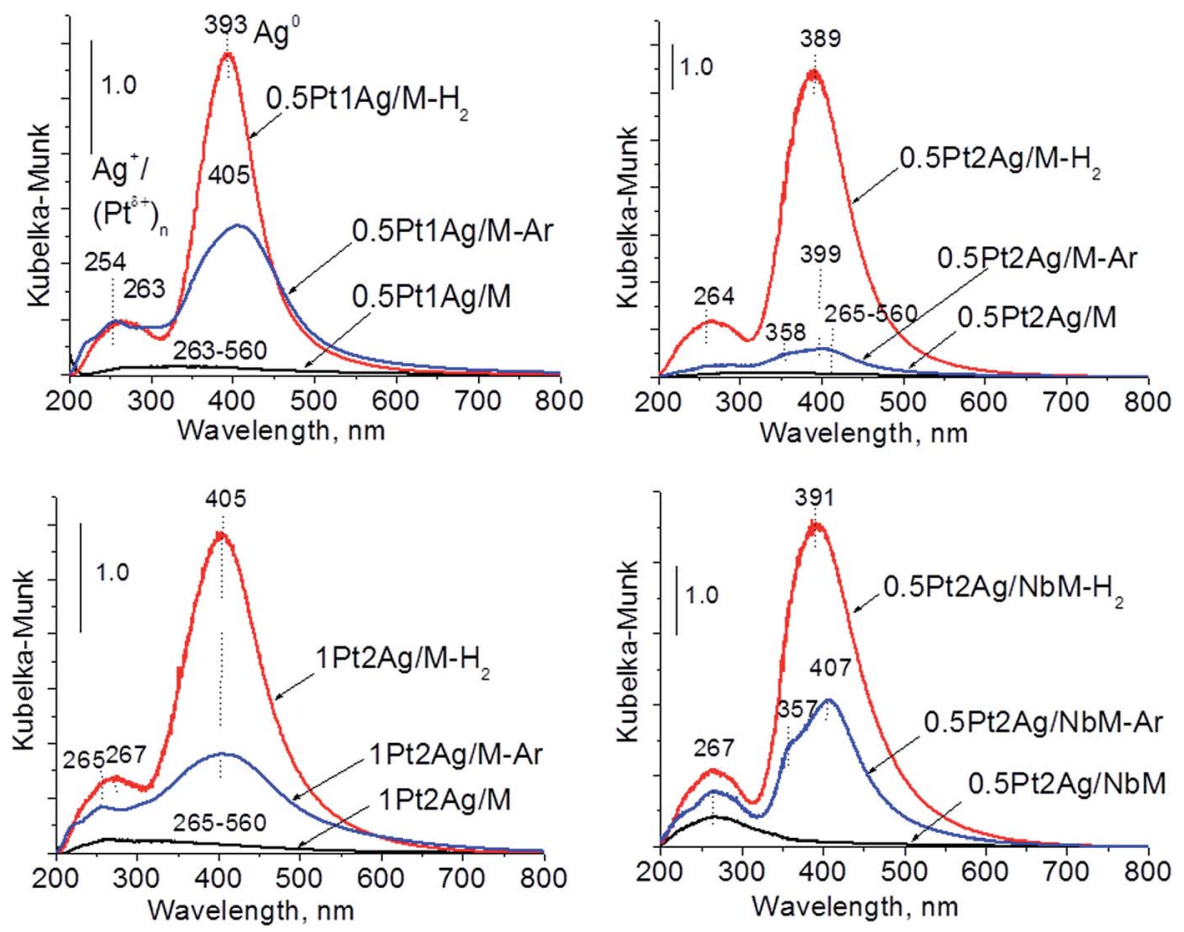

Fig. 8 UV-Vis DR spectra of bimetallic samples based on MCF and NbMCF after calcination and activation under argon or hydrogen flow. 
$373 \mathrm{~K}$

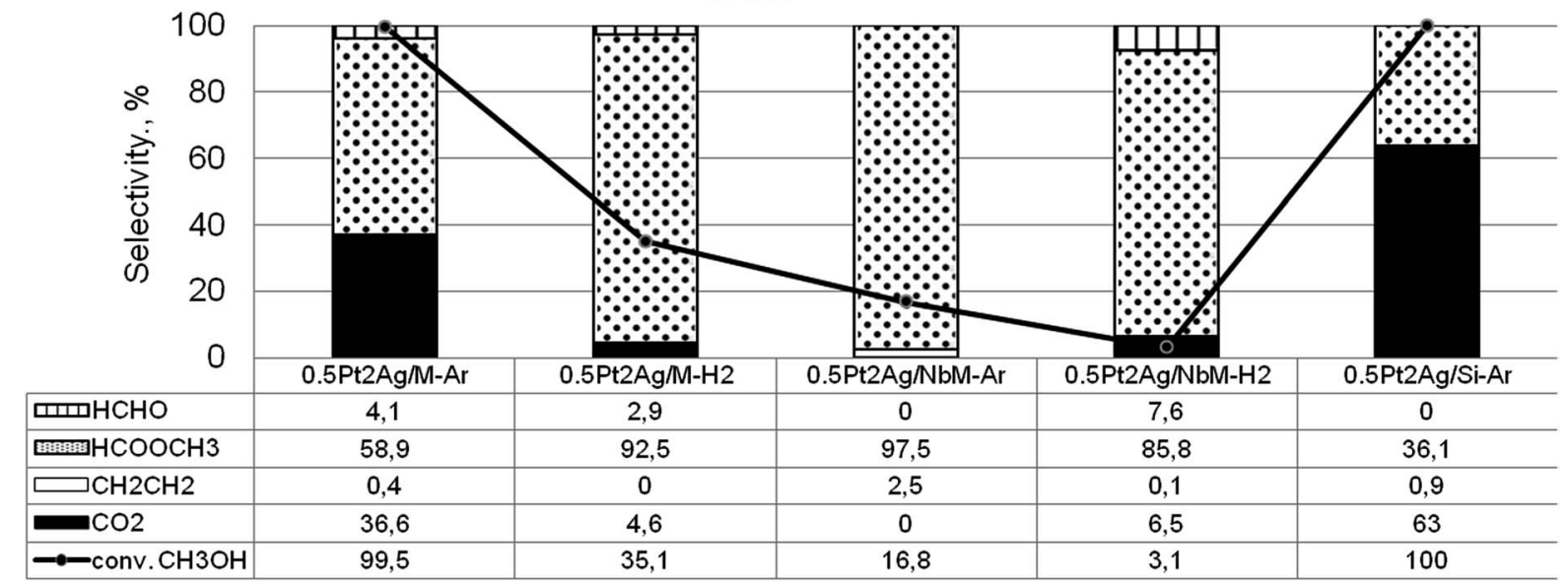

Fig. 9 Results of methanol oxidation $\left(\mathrm{O}_{2}: \mathrm{CH}_{3} \mathrm{OH}=2\right)$ - activity and selectivity for selected catalysts at $373 \mathrm{~K}$.

these materials in methanol oxidation performed after activation in argon or hydrogen flow in temperatures from $323 \mathrm{~K}$ to $523 \mathrm{~K}$. The data characterizing the activity and selectivity of the selected materials in methanol oxidation are presented in Table S2-SD. $\dagger$ The main reaction products were methyl formate (MF - the product of selective oxidation) and carbon dioxide $\left(\mathrm{CO}_{2}-\right.$ the product of total oxidation). The silica supports, both commercial and MCF, were inactive in the oxidation of methanol. Mesoporous cellular foam modified with niobium species showed negligible activity at higher temperatures ( $473 \mathrm{~K}$ and $523 \mathrm{~K}$ ). The activity of monometallic silver catalyst loaded on MCF activated under argon or hydrogen flow appeared to be significant starting from $473 \mathrm{~K}$ (Table S2-SD $\dagger$ ). The sample activated in argon flow revealed $89 \%$ of methanol conversion at $523 \mathrm{~K}$ and comparable selectivity to $\mathrm{CO}_{2}$ and $\mathrm{MF}$, whereas the catalyst activated in hydrogen flow exhibited $97 \%$ of methanol conversion and selectivity mainly to $\mathrm{CO}_{2}(97 \%)$. The greater reduction of silver species by hydrogen treatment resulted in total oxidation of methanol. At lower reaction temperatures the monometallic silver catalyst showed negligible activity. The activity increased when bimetallic samples were used as catalysts. As Fig. 9 shows, the two samples, 0.5Pt2Ag/M-Ar and $0.5 \mathrm{Pt} 2 \mathrm{Ag} / \mathrm{Si}-\mathrm{Ar}$, activated in argon flow, showed the highest activity at $373 \mathrm{~K}$ ( $c a .100 \%$ conversion of methanol). However, their selectivities were different. The main product obtained on $0.5 \mathrm{Pt} 2 \mathrm{Ag} / \mathrm{M}-\mathrm{Ar}$ was $\mathrm{MF}$ ( $59 \%$ of selectivity), whereas on $0.5 \mathrm{Pt} 2 \mathrm{Ag} /$ Si-Ar the selectivity to MF was lower (36\%). The latter catalyst was active mainly in total oxidation because this material activated in argon flow contained the separated platinum and silver metallic phases. Metallic platinum is responsible for high activity of the catalysts in total oxidation as it was concluded from literature ${ }^{31,33,55-59}$ and the results obtained on 0.5Pt/M-Ar (Table S2$\mathrm{SD} \dagger)$. The selective formation of MF requires stronger chemisorption of formaldehyde (FA) formed in the first step of the methanol oxidation ${ }^{60-63}$ which allows the following interaction with oxygen to form formic acid. The latter one can be transformed to methyl formate if it interacts with the second methanol molecule. Pt-Ag alloy and cationic silver revealed such properties presenting medium strength of active centers for formaldehyde chemisorption. Too strong chemisorption of formaldehyde can lead to the oxidation to $\mathrm{CO}_{2}$. The presence of Pt-Ag alloy exclusively on $0.5 \mathrm{Pt} 2 \mathrm{Ag} / \mathrm{M}-\mathrm{Ar}$ sample activated under argon flow before the reaction is the reason for the highest MF production over this catalyst. The selectivity to MF over this catalyst became higher $(73 \%)$ at $423 \mathrm{~K}$ because of the lower strength of MF chemisorption at higher temperature allowing easier desorption of the chemisorbed MF. Interestingly, the presence of niobium in the support decreased the activity at a lower reaction temperature. It is caused by the changes in texture parameters described in the above sections and the interaction between niobium and silver species which influenced both, the alloy concentration diminishing during activation and the texture of metallic silver.

The interesting information coming from Fig. 9 and Table $\mathrm{S} 2-\mathrm{SD} \dagger$ is the difference in the activity of the samples activated under argon flow and hydrogen flow. Hydrogen caused the higher reduction of cationic silver to metallic one and disappearance of Pt-Ag alloy, which resulted in the decrease of the catalyst activity in methanol oxidation.

The above described results concerning the metals states after activation under argon or hydrogen flow, imply that silver and platinum species on the surface of supports used were not stable upon activation. The question arises whether the new metallic species formed after activation are stable under the reaction conditions where oxygen is a reactant which can oxidize the metallic species, and formaldehyde (an intermediate product) can be a reducer of cationic species. The comparison of XRD patterns of the materials after activation and after the reaction of methanol oxidation clearly indicates that the active metal species are not changed considerably during the reaction (Fig. S8-SD†).

\section{Conclusions}

The composition of Pt-Ag mixture plays a crucial role in the formation of bimetallic alloy on the mesoporous cellular foams and amorphous silica. The excess of silver is necessary for this purpose. It was proved in this paper that $\mathrm{Pt}-\mathrm{Ag}$ alloy is formed if the $\mathrm{Ag} / \mathrm{Pt}$ molar ratio achieves a value of 2.5 or higher. The 
structure and composition of the silica support is less important for the formation of Pt-Ag alloy but it is crucial for its stability under activation conditions. It was documented that silica mesoporous cellular foam (MCF) used as the support allowed to preserve Pt-Ag alloy after activation under argon flow. The presence of bimetallic alloy in this catalysts resulted in a high activity and the highest selectivity to methyl formate in the low temperature ( $373 \mathrm{~K}$ and $423 \mathrm{~K}$ ) oxidation of methanol. The active phases formed after activation in argon or hydrogen flow were stable under the reaction conditions. The presence of niobium in the NbMCF support gave rise to the niobium-silver interaction leading to a decrease in the activity in methanol oxidation in spite of higher metal dispersion. The activation of bimetallic samples in argon or hydrogen flow caused partial segregation of platinum and silver present in Pt-Ag alloy. This effect was more pronounced after activation in hydrogen flow caused partial segregation of platinum and silver present in Pt$\mathrm{Ag}$ alloy. This effect was more pronounced after activation in hydrogen.

\section{Acknowledgements}

National Science Centre in Poland (Grants No. 2015/19/N/ST5/ 00501 and 2014/15/B/ST5/00167) are acknowledged for the financial support of this work.

\section{References}

1 V. Dal Santo, A. Gallo, A. Naldoni, M. Guidotti and R. Psaro, Catal. Today, 2012, 197, 190-205.

2 A. Wang, X. Liu, C. Mou and T. Zhang, J. Catal., 2013, 308, 258-271.

3 L. Guczi, J. Mol. Catal., 1984, 25, 13-29.

4 W. M. H. Sachtler, in Handbook of Heterogeneous Catalysis, 2008, pp. 313-320.

5 Z. Zhang, Z. Jiang and W. Shangguan, Catal. Today, 2016, 264, 270-278.

6 A. U. Nilekar, Y. Xu, J. Zhang, M. B. Vukmirovic, K. Sasaki, R. R. Adzic and M. Mavrikakis, Top. Catal., 2007, 276-284.

7 T. Moriya, J. Kugai, S. Seino, Y. Ohkubo, T. Nakagawa, H. Nitani and T. A. Yamamoto, J. Nanopart. Res., 2013, 15, 1-8.

8 R. P. Doherty, J.-M. Krafft, C. Méthivier, S. Casale, H. Remita, C. Louis and C. Thomas, J. Catal., 2012, 287, 102-113.

9 P. J. Van den Hoek, E. J. Baerends and R. a. Van Santen, J. Phys. Chem., 1989, 93, 6469-6475.

10 E. Cao, S. Firth, P. F. McMillan and A. Gavriilidis, Catal. Today, 2007, 126, 119-126.

11 D. Chen, Z. Qu, S. Shen, X. Li, Y. Shi, Y. Wang, Q. Fu and J. Wu, Catal. Today, 2011, 175, 338-345.

12 V. V. Dutov, G. V. Mamontov, V. I. Zaikovskii and O. V. Vodyankina, Catal. Today, 2015, 278, 150-156.

13 A. Q. Wang, C. M. Chang and C. Y. Mou, J. Phys. Chem. B, 2005, 109, 18860-18867.

14 W. P. Zeng, J. Tang, P. Wang and Y. Pei, RSC Adv., 2016, 6, 55867-55877.
15 T. Benkó, A. Beck, K. Frey, D. F. Srankó, O. Geszti, G. Sáfrán, B. Maróti and Z. Schay, Appl. Catal., A, 2014, 479, 103-111.

16 I. Sobczak and E. Dembowiak, J. Mol. Catal. A: Chem., 2015, 409, 137-148.

17 K. Kim, K. L. Kim and K. S. Shin, Analyzer, 2011, 2337423380.

18 Z. Peng, H. You and H. Yang, Adv. Funct. Mater., 2010, 20, 3734-3741.

19 J. B. Xu, T. S. Zhao and Z. X. Liang, J. Phys. Chem. C, 2008, 17362-17367.

20 G.-T. Fu, R.-G. Ma, X.-Q. Gao, Y. Chen, Y.-W. Tang, T.-H. Lu and J.-M. Lee, Nanoscale, 2014, 6, 12310-12314.

21 W. He, X. Wu, J. Liu, X. Hu, K. Zhang, S. Hou, W. Zhou and S. Xie, Chem. Mater., 2010, 22, 2988-2994.

22 B. J. Hwang, S. Murugesan, S. Kumar, C. Chen, R. Chang, D. Liu and J. Lee, J. Phys. Chem. C, 2008, 2370-2377.

23 S. Y. Hwang, C. Zhang, E. Yurchekfrodl and Z. Peng, J. Phys. Chem. C, 2014, 118, 28739-28745.

24 C. M. Doudna, M. F. Bertino, F. D. Blum, A. T. Tokuhiro, D. Lahiri-Dey, S. Chattopadhyay and J. Terry, J. Phys. Chem. B, 2003, 107, 2966-2970.

25 C. Guo and J. Hu, Appl. Phys. A, 2014, 809-813.

26 M. M. Jeff Greeley and J. K. Norskov, Annu. Rev. Phys. Chem., 1999, 50, 79-115.

27 U. B. Demirci, J. Power Sources, 2007, 173, 11-18.

28 L. Feng, G. Gao, P. Huang, X. Wang, C. Zhang, J. Zhang, S. Guo and D. Cui, Nanoscale Res. Lett., 2011, 6, 551.

29 V. V. Pryadchenko, V. V. Srabionyan, E. B. Mikheykina, L. A. Avakyan, V. Y. Murzin, Y. V. Zubavichus, I. Zizak, V. E. Guterman and L. A. Bugaev, J. Phys. Chem. C, 2015, 119, 3217-3227.

30 J. J. Lv, J. X. Feng, S. S. Li, Y. Y. Wang, A. J. Wang, Q. L. Zhang, J. R. Chen and J. J. Feng, Electrochim. Acta, 2014, 133, 407413.

31 J. Wisniewska, M. Ziolek, N. Artioli and M. Daturi, J. Catal., 2016, 336, 58-75.

32 P. Schmidt-Winkel, W. W. Lukens, D. Zhao, P. Yang, B. F. Chmelka and G. D. Stucky, J. Am. Chem. Soc., 1999, 121, 254-255.

33 J. Czaplinska, P. Decyk and M. Ziolek, Appl. Catal., A, 2015, 504, 361-372.

34 K. Stawicka, M. Trejda and M. Ziolek, Appl. Catal., A, 2013, 467, 325-334.

35 G. Valverde-Aguilar, J. a. García-Macedo and V. RenteríaTapia, J. Nano Res., 2008, 3, 103-114.

36 X. Chen, J. Chen, Y. Zhao, M. Chen and H. Wan, Chin. J. Catal., 2012, 33, 1901-1905.

37 X. Huang, M. Yang, G. Wang and X. Zhang, Microporous Mesoporous Mater., 2011, 144, 171-175.

38 C. H. Jung, J. Yun, K. Qadir, B. Naik, J. Y. Yun and J. Y. Park, Appl. Catal., B, 2014, 154-155, 171-176.

39 M. L. Wu and L. B. Lai, Colloids Surf., A, 2004, 244, 149-157. 40 Y. Borodko, C. M. Thompson, W. Huang, H. B. Yildiz, H. Frei and G. A. Somorjai, J. Phys. Chem. C, 2011, 115, 4757-4767.

41 P. M. More, D. L. Nguyen, M. K. Dongare, S. B. Umbarkar, N. Nuns, J. S. Girardon, C. Dujardin, C. Lancelot, 
A. S. Mamede and P. Granger, Appl. Catal., B, 2015, 162, 1120.

42 J. Gao, X. Ren, D. Chen, F. Tang and J. Ren, Scr. Mater., 2007, 57, 687-690.

43 D. C. Tranca, A. Wojtaszek-Gurdak, M. Ziolek and F. Tielens, Phys. Chem. Chem. Phys., 2015, 17, 22402-22411.

44 A. M. Ferraria, A. P. Carapeto and A. M. Botelho Do Rego, Vacuum, 2012, 86, 1988-1991.

45 V. K. Kaushik, J. Electron Spectrosc. Relat. Phenom., 1991, 56, 273-277.

46 G. B. Hoflund and Z. F. Hazos, Phys. Rev. B: Condens. Matter Mater. Phys., 2000, 62, 126-133.

47 X. Bao, M. Muhler, T. Schedel-Niedrig and R. Schlögl, Phys. Rev. B: Condens. Matter Mater. Phys., 1996, 54, 2249-2262.

48 V. La Parola, M. Kantcheva, M. Milanova and A. M. Venezia, J. Catal., 2013, 298, 170-178.

49 J. Cai, Y. Huang, B. Huang, S. Zheng and Y. Guo, Int. J. Hydrogen Energy, 2014, 39, 798-807.

50 X. Li, W. Zheng, H. Pan, Y. Yu, L. Chen and P. Wu, J. Catal., 2013, 300, 9-19.

51 A. Masson, B. Bellamy, Y. H. Romdhane, M. Che, H. Roulet and G. Dufour, Surf. Sci., 1986, 173, 479-497.
52 M. Chatterjee, T. Iwasaki, Y. Onodera and T. Nagase, Catal. Lett., 1999, 61, 199-202.

53 A. Ruban, H. Skriver and J. Nørskov, Phys. Rev. B: Condens. Matter Mater. Phys., 1999, 59, 15990-16000.

54 A. Monshi, World J. Nano Sci. Eng., 2012, 2, 154-160.

55 J. Zhu, T. Wang, X. Xu, P. Xiao and J. Li, Appl. Catal., B, 2013, 130-131, 197-217.

56 L. Usón, M. G. Colmenares, J. L. Hueso, V. Sebastián, F. Balas, M. Arruebo and J. Santamaría, Catal. Today, 2014, 227, 179-186.

57 Y. J. Mergler, A. Van Aalst, J. Van Delft and B. E. Nieuwenhuys, Appl. Catal., B, 1996, 10, 245-261.

58 A. Tsuji, K. T. V. Rao, S. Nishimura, A. Takagaki and K. Ebitani, ChemSusChem, 2011, 4, 542-548.

59 A. Fukuoka, J. Kimura, T. Oshio and Y. Sakamoto, J. Am. Chem. Soc., 2007, 10120-10125.

60 J. M. Tatibougt, Appl. Catal., A, 1997, 148, 213-252.

61 G. Busca, Catal. Today, 1996, 27, 457-496.

62 L. E. Briand, W. E. Farneth and I. E. Wachs, Catal. Today, 2000, 62, 219-229.

63 J. Florek-Milewska, P. Decyk and M. Ziolek, Appl. Catal., A, 2011, 393, 215-224. 